\title{
Learning Styles of Engineering Students, Online Learning Objects and Achievement
}

\author{
Malgorzata S. Zywno and M. F. (Frankie) Stewart \\ Ryerson University
}

\begin{abstract}
This paper presents the results of a research project investigating the effectiveness of an online learning object and identifying behavior patterns of engineering students with different learning styles that may affect their learning. Traditional instruction methods support only a narrow range of student learning styles. Instructional technology has a potential to expand the range of teaching strategies. The authors have been using multimedia in their teaching to enhance active learning and visualization, to provide students with improved formative feedback and review of the learned concepts despite challenges of increased class sizes. The study expanded on the previous research by allowing for direct observations of students' interactions with the learning object. The results were consistent with the framework developed by Felder and confirmed previous claims that multimedia add support for learners whose needs are not addressed by traditional instruction, while being also effective in addressing preferences of other types of learners.

Introduction

Learning Object Developed for the Study

One of the emerging trends in instructional technology is to focus on modular learning objects that can be shared among many users through online repositories. Canadian Co-operative Learning Object Exchange (CLOE) ${ }^{1}$ is an example of such an initiative. The online interactive Control Systems Tutorial Module developed by the investigators over the past year in collaboration with the in-house Digital Media Projects Office ${ }^{2}$ was partly sponsored by CLOE. The Module, intended as an additional learning resource tool for undergraduate engineering students, provides an interactive introduction to Control Systems with a mix of text and graphics, interactive animations and streaming video of real-world control systems (e.g. water tank level control, helicopter and inverted pendulum position control), followed by a self-scoring quiz to test the student comprehension of the reviewed concepts ${ }^{3}$.
\end{abstract}

Proceedings of the 2005 American Society for Engineering Education Annual Conference \& Exposition Copyright (C) 2005, American Society for Engineering Education 
Felder Learning Style Model and Instructional Technology

The Felder Learning Style Model identifies characteristics of the learners according to four categories: Active/Reflective, Sensing/Intuitive, Visual/Verbal and Sequential/Global ${ }^{4}$. The Felder-Soloman Index of Learning Styles (ILS), a psychometric instrument associated with the model, is freely available online ${ }^{5}$. Literature review, most notably of the work by Felder, shows that there is a mismatch between learning styles of engineering students, who are overwhelmingly Active, Sensing and Visual learners, and the traditional instruction methods still prevalent in engineering departments. Felder points out that teaching in a style that is consistently not supportive of the majority of learners, results in poor achievement, increased dropout rates and a loss of diversity among future engineers that would greatly benefit the profession. There is evidence that a balanced teaching style that addresses a wide range of learner preferences is most effective $^{4,6}$. Instructional technology has a potential to expand the range of teaching strategies, both directly, as is the case with dynamic visualization of engineering concepts and with asynchronous communications, or indirectly, by freeing up time for value-added activities in the classroom, thus addressing different learning styles.

The principal author has conducted extensive research into the learning styles of engineering students, using the Felder Model, which showed that that implementing hypermedia and online support in an engineering course resulted in an increased student achievement and satisfaction ${ }^{5,7}$. Those gains were attributed to a more engaging environment where an expanded range of learning styles was supported. However, constraints placed on that study by the desire to minimize the disruptiveness of an action research conducted in the context of a real curriculum, allowed for little direct observation of students' interactions with the multimedia materials used in the course. The current study, conducted in 2004, expanded on the previous research by allowing for such direct observations.

Methods

The primary goal of the study was to investigate the effectiveness of learner interactions with a learning object through observations and testing of participants with different learning style modalities. The investigators also wanted to obtain feedback regarding the usability of the Module, which is currently used in senior level Control Systems courses in the Mechanical and Electrical Engineering programs at Ryerson University, Ontario, Canada.

\section{Study Design}

Fifteen recently graduated students, five from a Mechanical Engineering program, and ten from an Electrical Engineering program participated in this project. Participation in the study was voluntary and all students were asked to sign an informed consent letter. Data collection consisted of three parts. In the first part, all students completed the ILS questionnaire, and a multiple choice pre-test based on the control theory covered in the on-line module. The goal was 
to identify their individual learning styles and set a benchmark for evaluating individual learning gains from interaction with the on-line module. Bloom's Taxonomy was employed to categorize the competence level required for the test questions, with a goal of comparing the results with previous research ${ }^{8}$. The second part consisted of individual sessions, during which participants' interactions with the module were videotaped and Talk Aloud Protocol (TAP) was used to gather their comments. TAP is a method of collecting data from participants during a usability test where the participants verbalize what they are thinking as they complete a task. Immediately following the individual session, each participant completed the post-test. The third part consisted of a debriefing session to obtain feedback from the participants on both the usability and instructional usefulness of the module. Learning style scores, student grade point averages along with their pre- and post-test scores were entered into a database for statistical analysis. All verbal data collected during the observations was quantified and also encoded. Processing of the collected data was divided into two stages, a preliminary quantitative analysis, to be followed by a qualitative analysis of the observations. It is important to stress that, while the sample size was not large enough to provide sufficient statistical power for a stand-alone quantitative data analysis, it is typical for a qualitative/usability study. Therefore, the rich visual data obtained from the taping of the sessions will be further analyzed using qualitative analysis that may possibly yield helpful insights.

Results

\section{Distributions of Learning Styles}

The participating students were either strongly or moderately Visual learners. They were also predominantly Active, Sensing and Sequential. Few were Reflective, Intuitive or Global learners. This is consistent with previous research ${ }^{4}$ and is documented in Table 1, Table 2 and Table3.

Table 1: Frequencies of Learning Style Scores

\begin{tabular}{|c|c|c|c|c|}
\hline & Active Score & Sensing Score & Visual Score & Sequential Score \\
\hline $\mathrm{N}$ & 15 & 15 & 15 & 15 \\
\hline Mean & 6.00 & 6.33 & 8.80 & 5.93 \\
\hline Median & 6.00 & 7.00 & 9.00 & 6.00 \\
\hline Std. Deviation & 2.33 & 2.26 & 1.47 & 1.91 \\
\hline Minimum & 2 & 2 & 6 & 2 \\
\hline Maximum & 10 & 9 & 11 & 9 \\
\hline & Reflective Score & Intuitive Score & Verbal Score & Global Score \\
\hline $\mathrm{N}$ & 15 & 15 & 15 & 15 \\
\hline Mean & 5.00 & 4.67 & 2.20 & 4.93 \\
\hline Median & 5.00 & 4.00 & 2.00 & 5.00 \\
\hline Std. Deviation & 2.33 & 2.26 & 1.47 & 1.83 \\
\hline Minimum & 1 & 2 & 0 & 2 \\
\hline Maximum & 9 & 9 & 5 & 9 \\
\hline
\end{tabular}


Table 2: Bimodal Distributions (either-or) $n=15$

\begin{tabular}{|l|l|l|l|}
\hline Active-Reflective & Sensing-Intuitive & Visual-Verbal & Sequential-Global \\
\hline $10-5$ & $10-5$ & $15-0$ & $10-5$ \\
\hline $66.7 \%-33.3 \%$ & $66.7 \%-33.3 \%$ & $100 \%-0 \%$ & $66.7 \%-33.3 \%$ \\
\hline
\end{tabular}

Table 3: Three-Step Distributions (either-balanced-or) $n=15$

\begin{tabular}{|l|l|l|l|}
\hline $\begin{array}{l}\text { Active-Balanced- } \\
\text { Reflective }\end{array}$ & $\begin{array}{l}\text { Sensing-Balanced- } \\
\text { Intuitive }\end{array}$ & $\begin{array}{l}\text { Visual-Balanced- } \\
\text { Verbal }\end{array}$ & $\begin{array}{l}\text { Sequential-Balanced- } \\
\text { Global }\end{array}$ \\
\hline $6-4-5$ & $9-3-3$ & $14-1-0$ & $6-7-2$ \\
\hline $40 \%-26.7 \%-33.3 \%$ & $60 \%-20 \%-20 \%$ & $93.3 \%-6.7 \%$ & $40 \%-46.7 \%-13.3 \%$ \\
\hline
\end{tabular}

Pre- and Post-Test Scores

During the first session all students took a 32 question multiple-choice pre-test on control theory covered in the upper level course they had completed from five to nine months previous to the study. In a scheduled individual session that followed within two weeks, each student was told to spend approximately 15 minutes navigating their way around and to verbalize their thoughts (i.e. using the Talk-Aloud Protocol) as they explored the module. Then they were given 45 minutes to study the actual control theory content of the tutorial module. Each navigation and study session was recorded on video for learning style and usability assessment. Immediately after the study session the student then completed the post-test consisting of the same 32 items. The pre- and post-test scores are documented in Table 4 and show that students benefited from studying the on-line module. Their post-test results showed improvements as compared with their pre-test results, with an average improvement of $18.7 \%$. This is consistent with previous research where the use of online supplementary materials contributed to statistically significant improvements in academic achievement scores ${ }^{6}$.

Table 4: Frequencies for Pre- and Post-Test Scores

\begin{tabular}{|c|c|c|c|c|c|c|c|c|}
\hline & N & Mean & Median & $\begin{array}{c}\text { Standard } \\
\text { Deviation }\end{array}$ & Min. & Max. & $\begin{array}{c}\text { Mean } \\
\text { in \% }\end{array}$ & $\begin{array}{c}\text { Possible } \\
\text { Score }\end{array}$ \\
\hline Pre-Quiz Score & 15 & 15.67 & 14.00 & 4.73 & 9 & 24 & $49.0 \%$ & 32 \\
\hline Post-Quiz Score & 15 & 21.60 & 21.00 & 5.03 & 12 & 29 & $67.5 \%$ & 32 \\
\hline Pre-Post Gain & 15 & 5.93 & 5.00 & 4.06 & -2 & 13 & $18.7 \%$ & 32 \\
\hline
\end{tabular}

The test questions were next reviewed and categorized according to Bloom's Taxonomy. Because of the small sample size, the responses were categorized into only two groupings (lower and higher cognitive skills), to allow for a more meaningful analysis. The lower cognitive skills group (19 out of 32) included 14 questions that were determined to be Level 2 (Comprehension), and five questions that were determined to be Level 3 (Application). The higher cognitive skills group (13 out of 32) included 11 questions that were determined to be Level 4 (Analysis) and two questions that were determined to be Level 6 (Evaluation). The pre- and post-quiz scores were then assessed for those two groups. As Table 5 and Table 6 show, test scores for the Preand Post-test, as well as score gains, were higher for lower cognitive levels than for higher ones. 
This observation is consistent with the previous research, where larger improvements in course scores were observed at lower cognitive levels ${ }^{8}$.

Table 5: Frequencies for Pre-Post Scores at Lower vs. Higher Levels of Bloom's Taxonomy

\begin{tabular}{|l|l|l|l|l|}
\hline & $\begin{array}{l}\text { Bloom Lower Levels } \\
\text { Pre-test }\end{array}$ & $\begin{array}{l}\text { Bloom Lower Levels } \\
\text { Post-test }\end{array}$ & $\begin{array}{l}\text { Bloom Higher Levels } \\
\text { Pre-test }\end{array}$ & $\begin{array}{l}\text { Bloom Higher Levels } \\
\text { Post-test }\end{array}$ \\
\hline $\mathrm{N}$ & 15 & 15 & 15 & 15 \\
\hline Mean & 9.60 & 13.53 & 5.13 & 7.07 \\
\hline Median & 10.00 & 13.00 & 4.00 & 7.00 \\
\hline Std. Deviation & 2.56 & 2.80 & 2.90 & 2.74 \\
\hline Minimum & 5 & 10 & 1 & 1 \\
\hline Maximum & 13 & 17 & 11 & 12 \\
\hline Mean in \% & $53.3 \%$ & $75.2 \%$ & $39.5 \%$ & $54.4 \%$ \\
\hline Possible Score & 19 & 19 & 13 & 13 \\
\hline
\end{tabular}

Table 6: Pre-Post Gains at Different Levels of Bloom's Taxonomy

\begin{tabular}{|l|l|l|l|l|l|l|}
\hline & $\begin{array}{l}\text { Bloom Level 2 } \\
\text { post-pre gain }\end{array}$ & $\begin{array}{l}\text { Bloom Level 3 } \\
\text { post-pre gain }\end{array}$ & $\begin{array}{l}\text { Bloom Level 4 } \\
\text { post-pre gain }\end{array}$ & $\begin{array}{l}\text { Bloom Level 6 } \\
\text { post-pre gain }\end{array}$ & $\begin{array}{l}\text { Bloom Lower } \\
\text { Levels gain }\end{array}$ & $\begin{array}{l}\text { Bloom Higher } \\
\text { Levels gain }\end{array}$ \\
\hline $\mathrm{N}$ & 15 & 15 & 15 & 15 & 15 & 15 \\
\hline Mean & 2.47 & 1.53 & 2.07 & -.13 & 4.00 & 1.93 \\
\hline Median & 3.00 & 2.00 & 1.00 & .00 & 4.00 & 1.00 \\
\hline Std. Deviation & 1.81 & 1.51 & 2.37 & .74 & 2.39 & 2.58 \\
\hline Minimum & -1 & -2 & -3 & -1 & 0 & -3 \\
\hline Maximum & 5 & 4 & 6 & 2 & 7 & 6 \\
\hline Mean in \% & $17.6 \%$ & $30.6 \%$ & $18.8 \%$ & $-0.7 \%$ & $21.1 \%$ & $14.8 \%$ \\
\hline Possible Score & 14 & 5 & 11 & 2 & 19 & 13 \\
\hline
\end{tabular}

The pre-post test gains were then investigated with respect to the type of question: was the question "Visual", i.e. requiring assessment of pictures, diagrams, etc., or "Verbal" - requiring assessment of a written explanation? Or was the question "Sensing", i.e. requiring assessment of facts or details by set equations, etc., or "Intuitive", i.e. requiring assessment of more abstract formulations? There were 14 "Visual" questions versus 18 "Verbal" ones and 19 "Sensing" questions versus 13 "Intuitive" ones. The analysis is shown in Table 7 and Table 8.

Table 7: Frequencies for Pre-Post Scores for Visual and Verbal Type of Questions

\begin{tabular}{|c|c|c|c|c|}
\hline & Visual Q.: Pre-test & Visual Q.: Post-test & Verbal Q.: Pre-test & Verbal Q.: Post-test \\
\hline $\mathrm{N}$ & 15 & 15 & 15 & 15 \\
\hline Mean & 6.53 & 8.93 & 9.13 & 12.60 \\
\hline Median & 6.00 & 9.00 & 8.00 & 12.00 \\
\hline Std. Deviation & 2.61 & 2.87 & 2.59 & 2.53 \\
\hline Minimum & 3 & 2 & 5 & 8 \\
\hline Maximum & 11 & 14 & 14 & 16 \\
\hline Mean in \% & $46.6 \%$ & $63.8 \%$ & $56.6 \%$ & $70 \%$ \\
\hline Possible Score & 14 & 14 & 18 & 18 \\
\hline
\end{tabular}

Scores for each type of question improved from pre- to post-test. The largest improvement was observed for the Sensing type questions, as shown in Table 9. This was understandable, as the

Proceedings of the 2005 American Society for Engineering Education Annual Conference \& Exposition Copyright (C) 2005, American Society for Engineering Education 
interaction with the on-line module would provide the students with a refresher in the set mathematical formulations of control theory.

Table 8: Frequencies for Pre-Post Scores for Sensing and Intuitive Type of Questions

\begin{tabular}{|c|c|c|c|c|}
\hline & Sensing Q.: Pre-test & Sensing Q.: Post-test & Intuitive Q.: Pre-test & Intuitive Q.: Post-test \\
\hline $\mathrm{N}$ & 15 & 15 & 15 & 15 \\
\hline Mean & 10.53 & 14.53 & 5.13 & 7.07 \\
\hline Median & 11.00 & 14.00 & 4.00 & 7.00 \\
\hline Std. Deviation & 2.64 & 2.80 & 2.90 & 2.74 \\
\hline Minimum & 6 & 11 & 1 & 1 \\
\hline Maximum & 14 & 18 & 11 & 12 \\
\hline Mean in \% & $55.4 \%$ & $76.5 \%$ & $39.5 \%$ & $54.4 \%$ \\
\hline Possible Score & 19 & 19 & 13 & 13 \\
\hline
\end{tabular}

Table 9: Frequencies for Pre-Post Gains for Visual, Verbal, Sensing and Intuitive Type of Questions

\begin{tabular}{|c|c|c|c|c|}
\hline & $\begin{array}{c}\text { Visual Q. } \\
\text { post-pre gain }\end{array}$ & $\begin{array}{c}\text { Verbal Q. } \\
\text { post-pre gain }\end{array}$ & $\begin{array}{c}\text { Sensing Q. post- } \\
\text { pre gain }\end{array}$ & $\begin{array}{c}\text { Intuitive Q. } \\
\text { post-pre gain }\end{array}$ \\
\hline $\mathrm{N}$ & 15 & 15 & 15 & 15 \\
\hline Mean & 2.40 & 3.47 & 4.00 & 1.93 \\
\hline Median & 2.00 & 4.00 & 4.00 & 1.00 \\
\hline Std. Deviation & 2.64 & 2.47 & 2.39 & 2.58 \\
\hline Minimum & -3 & 0 & 0 & -3 \\
\hline Maximum & 7 & 8 & 7 & 6 \\
\hline Mean in \% & $17.1 \%$ & $19.2 \%$ & $21 \%$ & $14.8 \%$ \\
\hline Possible Score & 14 & 18 & 19 & 13 \\
\hline
\end{tabular}

The achievement gains of the students were then correlated with their different learning styles. As seen in Table 10, all learning styles posted gains between the pre- and post-tests, though there was no data for Verbal students, absent in this study group.

Table 10: Achievement Gains for Different Learning Styles

\begin{tabular}{|c|c|c|c|c|c|c|c|}
\hline Gains & Active & Reflective & Sensing & Intuitive & Visual & Sequential & Global \\
\hline Pre-Post & 6.1 & 5.6 & 7.0 & 3.8 & 5.93 & 6.2 & 5.4 \\
\hline Bloom Lower & 3.9 & 4.2 & 3.9 & 4.2 & 4 & 3.9 & 4.2 \\
\hline Bloom Higher & 2.2 & 1.4 & 3.1 & -0.4 & 1.93 & 2.3 & 1.2 \\
\hline Visual questions & 2.6 & 2.0 & 3.3 & 0.6 & 2.4 & 2.7 & 1.8 \\
\hline Verbal questions & 3.4 & 3.6 & 3.6 & 3.2 & 3.2 & 3.3 & 3.8 \\
\hline Sensing Questions & 3.9 & 4.2 & 3.9 & 4.2 & 4. & 3.9 & 4.2 \\
\hline Intuitive questions & 2.2 & 1.4 & 3.1 & -0.4 & 1.9 & 2.3 & 1.2 \\
\hline
\end{tabular}

No statistically significant differences between the opposite modalities of Active/Reflective, Sensing/Intuitive and Sequential/Global were observed. Reflective students had higher scores than Active students on both pre- and post test in all Bloom's cognitive categories. However, Active students improved more on total pre-post gain, on visual and intuitive type questions, and on higher cognitive level questions. Similarly, Sequential students had higher scores than Global on both pre- and post test in all cognitive levels. However, Global students improved more on 
lower cognitive level questions, and on verbal type and sensing type questions. Intuitive students had higher scores than Sensing students on total pre-test score, on visual type questions in pretest, in higher cognitive level questions in pre-test, and in intuitive type questions on pre-test. However, Sensing students improved more overall, on higher cognitive level questions, on visual type, verbal type and intuitive type questions, and actually had higher post-scores overall, on higher cognitive level questions in the post-test, on visual type questions and intuitive type questions in the post-test.

\section{Usability Assessment}

The Talk Aloud Protocol (TAP) provided extensive feedback on the usability of the on-line module. Overall, 14 out of 15 students found something confusing in the tutorial. All comments have been reviewed and changes made to improve the module usability. During the debriefing session it was identified that some students study session was guided by their recall of questions from the pre-quiz tutorial as opposed to simply studying the theory in the module. Of the 14 students who answered this question, nine spent less than half their time preparing for the quiz, while five students spent more than half their time preparing for the quiz. There was a strong correlation between the time spent preparing for the quiz, and both pre-test score and post-test scores, $(\mathrm{r}=0.684, \mathrm{n}=14, \mathrm{p}=0.007$, and $\mathrm{r}=0.534, \mathrm{n}=14, \mathrm{p}=0.049$, respectively). While the latter is understandable, the former is not, since the pre-test was written before the students saw the module. The question is then about causality - what is cause and what is effect. The only explanation may be that those who did well on both tests were outcome-driven, and the reason they did well on tests is that they studied to the test, so given the chance here they did so as well.

On the other hand, the pre-post test gains were negatively correlated with the time spent studying the quiz section $(\mathrm{r}=-0.138, \mathrm{n}=14, \mathrm{p}=0.637)$, i.e. the more time was spent browsing looking for the answers, the smaller the gain was. This is not so counter-intuitive if we note that the pre-post gain is also negatively correlated with the pre-test score $(r=-0.354, n=14, p=0.195)$. Those who gained little had high scores already. On the other hand, those that did poorly on the pre-test, gained the most. They may also be less goal-oriented and therefore were less likely to study to the test. This observation is consistent with the previous research, where the largest learning gains were observed among lower-achieving students ${ }^{6,7}$.

Although no correlations between scores and answers to any of the questions have a level of statistical significance, it was observed that the higher the Grade Point Average, the more the students liked the layout, as well as the module itself. The lower the students' academic standing, the more likely they were to complain about the layout of the module. 


\section{Summary}

Interacting with the on-line module seemed to have benefited the students, with post-test results showing statistically significant improvements as compared with the pre-test results. While the small sample size and the fact that students had studied this material before, does not allow to draw far-reaching conclusions from that observation alone, it is very consistent with the previous study, where statistically significant learning gains were observed in a course where students were taught using a wide range of strategies, including multimedia and online resources ${ }^{6,7}$. Learning gains at lower cognitive levels of Bloom's Taxonomy were larger than at higher cognitive levels. This observation was again consistent with the previous work ${ }^{8}$, and led us to conclude that the module seems to be more effective in helping students solidify their knowledge at the lower cognitive levels, i.e. recall, comprehension and application.

Learning gains were also observed for all individual learning styles, indicating that all students, regardless of their learning style, may benefit from interactions with the on-line module. This observation is also consistent with the previous study, where a hypothesis was tested, and accepted, that interactive multimedia tools effectively address a wide range of learning styles and thus help benefit learning of all students ${ }^{6,7}$. Active, Sensing and Global learners had higher gain improvements in several categories. This observation is consistent with assertions in the literature that Active, Sensing and Global learners are the main beneficiaries of a teaching style that includes a mix of different strategies and expands on the conventional, text-based, passive lecturing ${ }^{4}$. In particular, working with the module seems to have benefited the Sensing students, who not only had higher gain improvements overall, but actually had higher post-test scores in several categories.

\section{Conclusions and Recommendations}

The study results were very promising, because, unlike the previous investigations, the study format allowed the investigators to observe first-hand how the students interacted with the object. Usability feedback obtained from the participants brought us immediate benefits in our goal of creating a user-friendly and valuable learning object. The comments from volunteers regarding the usability of the object have already been implemented. Quantitative data analysis presented here completed the first, preliminary stage of the study. In the second stage, the authors will further analyze the visual data obtained from the taping of the sessions using qualitative analysis, which may yield further helpful insights. The authors are planning to follow this small study with a large scale longitudinal analysis of learning styles and teaching strategies across several engineering disciplines, particularly looking at implementations of instructional technology in teaching and to combine it with analysis of the emotional maturity of students entering engineering programs. Based on those, the authors hope to provide recommendations on the remedial actions that would improve retention rates and diversity of the student body in engineering programs. 
Bibliography

1. CLOE (Co-operative Learning Objects Exchange) - Online Learning Objects Repository at University of Waterloo, Canada. Accessed January 4, 2005, at: http://cloe.on.ca/

2. Digital Media Projects Office, Ryerson University. Accessed January 4, 2005, at: http://www.ryerson.ca/dmp/

3. Zywno, M.S. \& Stewart, M.F., (2004). Work in Progress: Development, Implementation and Evaluation of a Learning Object for Teaching Control Systems, Session 1793, Proceedings of 2004 ASEE Annual Conference and Exposition, Salt Lake City, Utah.

4. Felder, R.M. \& Silverman, L.K., Learning and Teaching Styles in Engineering Education, Journal of Engineering Education, Vol. 78, No. 7, pp. 674-681, (1988).

5. Felder, R.M. \& Soloman, B.A., Index of Learning Styles Questionnaire, North Carolina State University, (2001). Accessed January 4, 2005, at: http://www2.ncsu.edu/unity/lockers/users/f/felder/public/ILSdir/ILS-a.htm

6. Zywno, M.S., (2002). Improving Student Outcomes through Hypermedia Instruction - a Comparative Study, British Journal of Engineering Education, UK, Vol. 3, No. 1, pp. 25-33.

7. Zywno, M.S., (2002). Instructional Technology, Learning Styles and Academic Achievement, Session 2422, Proceedings of 2002 ASEE Annual Conference and Exposition, Montreal, Quebec. Co-Winner of the Best Overall Paper at the Conference Award and Best Paper Award for Professional Interest Council V: Continuing Professional Development.

8. Zywno, M.S., (2003). Hypermedia Instruction and Learning Outcomes at Different Levels of Bloom's Taxonomy of Cognitive Domain, Global Journal of Engineering Education, Australia, Vol. 7, No. 1, pp. 59-70.

\section{MALGORZATA S. (GOSHA) ZYWNO}

Gosha Zywno, M.Eng. (U. of Toronto), Ph.D. (Glasgow Caledonian U.), is a Professor of Electrical and Computer Engineering at Ryerson University. Dr. Zywno has authored numerous papers and presentations on engineering education. She is a recipient of several university, national and international teaching excellence awards and a winner of eight best paper awards, including the Best Paper Award at the 2002 Annual ASEE Conference. Professor Zywno is a member of the ASEE, STLHE, Senior Member of the IEEE, and a registered Professional Engineer.

\section{M.F. (FRANKIE) STEWART}

Frankie Stewart, B.A.Sc. (Queen's U.), M.Eng. (U. of Toronto), is a Professor of Mechanical and Industrial Engineering at Ryerson University. Her current research interests involve recruitment and retention of women in engineering and multimedia applications in control education. Professor Stewart is a member of SME, a registered Professional Engineer. 